\title{
Hemangiomas of the Pelvis
}

\author{
Marcus C.B. Tan, M.B., B.S. ${ }^{1}$ and Matthew G. Mutch, M.D. ${ }^{1}$
}

\begin{abstract}
Hemangiomas of the colon and rectum are rare but often misdiagnosed causes of hematochezia. They are characterized by the clinical triad of recurrent episodes of painless rectal bleeding, multiple ectopic phleboliths on plain radiographs, and cutaneous hemangiomas. The majority of these tumors involve the rectosigmoid region. Diffuse cavernous lesions are the most common histological type. Endoscopy is important to define the extent and number of lesions. Imaging by computed tomography or magnetic resonance imaging is used to define invasion into pelvic structures. Surgical resection with preservation of the sphincters is the recommended treatment.
\end{abstract}

KEYWORDS: Hemangioma, colon, rectum

Objectives: Upon completion of this article, the reader should be able to summarize the diagnosis and management of colorectal hemangiomas.

\section{INCIDENCE}

Hemangiomas are benign tumors made up of mature well-formed vessels usually lined by a single layer of endothelium. ${ }^{1}$ They are among the rarest tumors of the lower gastrointestinal (GI) tract. Phillips ${ }^{2}$ described the first such case in 1839, of an 18-year-old man who presented with hemorrhage from an ulcerated anal hemangioma. Suture ligation of the lesion led to sloughing of the tumor and resolution of symptoms. Of the 255 cases of gastrointestinal hemangiomas Gentry et $\mathrm{al}^{3}$ identified in their exhaustive 1949 review of the literature and the Mayo experience, only 96 involved the colon, rectum, or anus. This number had increased to about 300 in the review by Coppa et $\mathrm{al}^{4}$ in 1984 . Fifty percent of large intestinal hemangiomas are rectal in location. ${ }^{5,6}$

Intestinal hemangiomas are important because of their potential for causing massive hemorrhage. ${ }^{3,7-11}$ Early reports cite a 40 to $50 \%$ mortality in untreated cases. ${ }^{3,12,13}$ Death from exsanguination has been described. ${ }^{7,14}$ These tumors are difficult to diagnose, and rectal lesions in particular are frequently misdiagnosed and mismanaged. ${ }^{15}$ Indeed, in reviewing 47 pediatric cases of intestinal hemangiomas, Nader and Margolin ${ }^{16}$ found that the average time between onset of symptoms and correct diagnosis was 16 years. Jeffery et $\mathrm{al}^{17}$ found that $80 \%$ of patients who were finally diagnosed with a colorectal hemangioma had undergone a minimum of one inappropriate surgical procedure as a result of incorrect diagnosis. The triad of intermittent hematochezia, multiple ectopic phleboliths, and cutaneous hemangiomas should make the physician suspicious of a hemangioma as the cause of GI hemorrhage. ${ }^{18}$

\section{DEMOGRAPHICS}

Although intestinal hemangiomas overall are about 2.5 times more common in men than women, this
${ }^{1}$ Section of Colon and Rectal Surgery, Department of Surgery, Washington University School of Medicine, St. Louis, Missouri. Address for correspondence and reprint request: Matthew G. Mutch, M.D., Section of Colon and Rectal Surgery, Department of Surgery, Washington University School of Medicine, 660 S. Euclid Ave., Campus Box 8109, St. Louis, MO 63110. E-mail: mutchm@ wudosis.wustl.edu.
Uncommon Colorectal Neoplasms; Guest Editor, Matthew G. Mutch, M.D.

Clin Colon Rectal Surg 2006;19:94-102. Copyright (C) 2006 by Thieme Medical Publishers, Inc., 333 Seventh Avenue, New York, NY 10001, USA. Tel: +1(212) 584-4662.

DOI 10.1055/s-2006-942350. ISSN 1531-0043. 
Table 1 Cutaneous Syndromes Associated with Gastrointestinal Hemangiomas

\begin{tabular}{|c|c|c|}
\hline Syndrome & Inheritance & Characteristics \\
\hline $\begin{array}{l}\text { Blue rubber bleb nevus syndrome } \\
\text { (BRBNS) }\end{array}$ & $\begin{array}{l}\text { Most cases are sporadic, but families } \\
\text { with autosomal dominant have been } \\
\text { described. Putative genetic defect } \\
\text { on chromosome } 9 \text {. }\end{array}$ & $\begin{array}{l}\text { Cavernous hemangiomas of the skin, } \\
\text { gastrointestinal tract, other viscera. } \\
\text { Cutaneous lesions are blue, tender lesions } \\
0.5-5 \mathrm{~cm} \text { in diameter-with compression, } \\
\text { blood can be emptied out of them. A recent } \\
\text { case report has suggested that pregnancy } \\
\text { may induce intestinal hemangiomas to bleed. }\end{array}$ \\
\hline Klippel-Trenaunay-Weber syndrome & Sporadic & $\begin{array}{l}\text { Triad of cutaneous hemangiomas, bone and } \\
\text { soft-tissue hypertrophy of the lower } \\
\text { extremities, and congenital varicose veins. }\end{array}$ \\
\hline $\begin{array}{l}\text { HHT (Osler-Rendu-Weber syndrome) } \\
\qquad \text { (Nader and Margolin 1966) }^{16}\end{array}$ & Autosomal dominant & $\begin{array}{l}\text { Mucocutaneous telangiectasia especially } \\
\text { oral, nasal. Hemangiomatous lesions } \\
\text { have been found in the stomach, small } \\
\text { intestine, and rectum. }\end{array}$ \\
\hline
\end{tabular}

does not seem to be the case specifically for colorectal hemangiomas, for which there is a roughly equal sex distribution. ${ }^{3}$ A significant proportion of patients are symptomatic from childhood, but the diagnosis is often not made until adulthood. Thus, there is a wide age range at time of definitive diagnosis, from 2 months of age up to 79 years. $3,5,19$

\section{ASSOCIATIONS}

Hemangiomas of the colon and rectum can occur as solitary or multiple lesions. There may be synchronous lesions of the stomach and small intestine. They may be a part of a multicentric process with involvement of the spleen, kidney, brain, and skin. ${ }^{20,21}$

The association of cutaneous lesions with GI hemangiomas was first recognized by Gascoyen ${ }^{22}$ in 1860. Since then, several syndromes have been described, including blue rubber bleb nevus syndrome (BRBNS), Klippel-Trenaunay-Weber syndrome, and Peutz-Jeghers syndrome (see Table 1). However, cutaneous hemangiomas are rarely ( $1.8 \%$ of cases) associated with intestinal visceral hemangiomas. ${ }^{23}$

There is a well-established connection between the use of conjugated estrogens, as found in the oral contraceptive pill, and the growth of hepatic hemangiomas. No such association has been described for intestinal hemangiomas.

\section{CLASSIFICATION}

Building on the work of Kaijser, ${ }^{24}$ intestinal hemangiomas have been divided into several categories $3,18,20,25,26$ :

- Capillary

- Cavernous

Localized (polypoid or nonpolypoid)
Diffuse infiltrating (expansive)

Multiple phlebectasia

- Mixed

- Hemangiomatosis

\section{MICROSCOPIC AND MACROSCOPIC PATHOLOGY}

Almost all intestinal hemangiomas are polypoid and intraluminal; the occasional solitary tumor may be annular, encircling the bowel wall. They range in color from red to purple and are soft and compressible unless they are thrombosed and contain phleboliths. The normally pink-tan mucosa adjacent to the tumor is often congested and edematous. ${ }^{3}$

Capillary hemangiomas constitute 5 to $10 \%$ of benign vascular tumors of the GI tract. ${ }^{3,6,27}$ They consist of small, thin-walled, densely packed vessels located in and originating from the submucosal vascular plexus. Vessels are lined with a single layer of well-differentiated endothelium. There is minimal surrounding connective tissue, especially with regard to smooth muscle and elastin. Capillary hemangiomas are more common in the small intestine, appendix, and perianal skin. They are usually solitary and, despite appearing well circumscribed, lack a true capsule. Mucosal ulceration is present in 50\%. Edema and chronic inflammatory changes in the overlying mucosa can make diagnosis difficult. The lining endothelial cells are immunoreactive with antibodies to factor VIII-related antigen. ${ }^{6}$

Cavernous hemangiomas, although similarly located in the submucosa, consist of larger vessels with a predilection for forming blood-filled sinuses. There may be a single or multiple layers of flattened endothelial cells, with scant interstitial tissue. ${ }^{28}$ Thrombosis within these tumors is common. They constitute one third of all benign vascular tumors of the GI tract. ${ }^{29}$ Three subtypes 


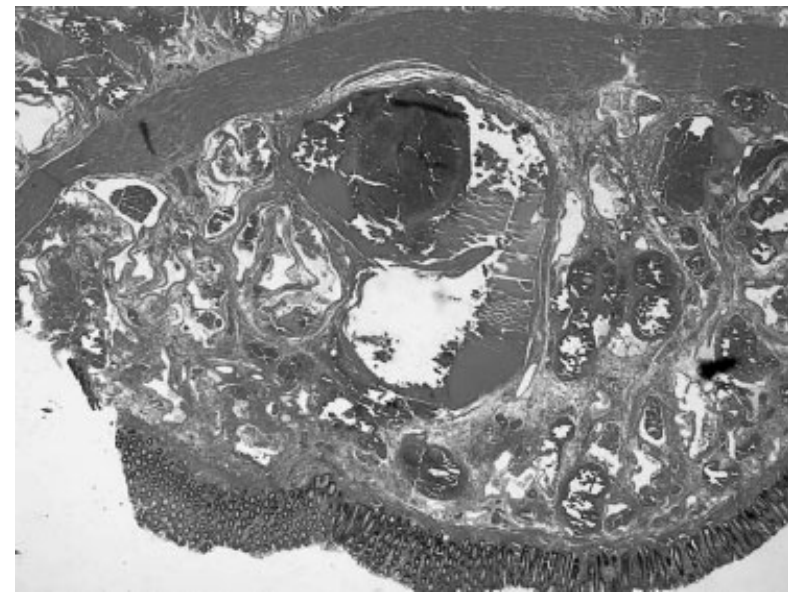

Figure 1 Cavernous hemangioma. Photomicrograph showing the dilated, congested submucosal vessels characteristic of this type of hemangioma. (Courtesy of Dr. J. Ritter, St. Louis, MO.)

have been described. Localized cavernous hemangiomas, when polypoid, are usually sufficiently large to be symptomatic. The diffuse expansive type (see Fig. 1) typically extends along some 20 to $30 \mathrm{~cm}$ of intestine and may be multiple. The rectum is involved in $70 \%$ of cases, ${ }^{3}$ in which there may be involvement of the entire thickness of the intestinal wall and infiltration into surrounding structures. ${ }^{4,6}$ The term "multiple phlebectasia" refers to the presence of multiple discrete tumors less than $1 \mathrm{~cm}$ in diameter.

Mixed hemangiomas constitute 5 to $10 \%$ of benign intestinal vascular tumors. They share variable features of both capillary and cavernous hemangiomas and have a distribution similar to that of the former. They are typically polypoid. ${ }^{6}$

Disseminated intestinal hemangiomatosis refers to the presence of more than 50 intestinal hemangiomas spread throughout the GI tract. Histologically, they are usually of the cavernous type. These lesions are part of a syndrome of disseminated hemangiomatosis affecting three or more systems. Patients typically present at birth with numerous cutaneous hemangiomas. ${ }^{6}$

\section{PATHOPHYSIOLOGY}

Colorectal hemangiomas are congenital, arising from embryonic sequestrations of mesodermal tissue. They enlarge by the proliferation of their endothelial cells, impinging upon the overlying mucosa as well as the muscularis beneath. The different histological types reflect anomalies occurring at different stages of stem cell development - capillary hemangiomas at the initial stage, cavernous at the second stage. ${ }^{18}$

The vascular channels of hemangiomas, probably through a combination of disordered blood flow and abnormal endothelium, initiate the coagulation cascade. This leads to platelet sequestration, ${ }^{30}$ systemic thrombocytopenia, and a coagulopathy similar to disseminated intravascular coagulopathy (DIC), with depletion of fibrinogen and factors V and VIII. ${ }^{4,31}$ The triad of a rapidly enlarging hemangioma, thrombocytopenia, and coagulopathy is known as KasabachMerritt syndrome. Despite being extremely rare, it is associated with a 30 to $40 \%$ mortality rate related to uncontrollable hemorrhage. ${ }^{20}$ Management involves stabilization of hemostasis by replacing consumed clotting factors and platelets while trying to remove or ablate the lesion. For the latter, options described include angiographic embolization, steroids, interferon- $\alpha$, and chemotherapy. Use of anticoagulants, as in DIC, remains controversial. ${ }^{32}$

Local thrombus formation may fragment reticulocytes, which may lead to a microangiopathic hemolytic anemia. Microvascular obstruction of the submucosa and overlying mucosa may cause segmental ischemia and secondary inflammatory changes. ${ }^{31}$

Numerous reports have described invasion of the hemangioma into surrounding structures, particularly the bladder, uterus, and sacrum. ${ }^{11,33-35}$ Gentry et $\mathrm{al}^{3}$ also reported two patients who developed rectovaginal fistulas.

Erosion or ulceration into the abnormal vessels that constitute the hemangioma leads to profuse bleeding because of the lack of muscular and supportive elastic tissue in the walls.

Malignant transformation is exceedingly rare. ${ }^{21}$

\section{CLINICAL FEATURES}

\section{History}

Eighty percent of hemangiomas are symptomatic. Their outstanding clinical feature is intraluminal hemorrhage. ${ }^{6,36}$ Recurrent episodes of painless bleeding are characteristic and occur in 60 to $90 \%$ of cases. Episodes begin in childhood and are recurrent throughout adolescence, becoming progressively more severe. ${ }^{4}$ Most reported cases present with large-volume hematochezia. More than $50 \%$ of patients demonstrate evidence of chronic, iron deficiency anemia. ${ }^{25}$

In general, the cavernous type tend to bleed massively much more frequently than the capillary type because of their greater size and larger blood volume. Distal (i.e., rectal) lesions are more frequently symptomatic than more proximal lesions.

Bleeding occurs because of erosion of the walls of the abnormal vasculature through the mucosa into the intestinal lumen. As stool moves distally through the colon it solidifies, which can lead to greater trauma to the mucosal surface. This helps to explain why distal lesions are more likely to bleed than right colon or small intestinal lesions. However, in rare cases of transmural hemangiomas, rupture can occur on the serosal surface, leading to retroperitoneal or intraperitoneal hemorrhage. 
It is important to note that the size of a hemangioma does not always correlate with the amount or rate of bleeding. Condon and Loyd ${ }^{37}$ described a patient with massive hematochezia from a single $1.8-\mathrm{cm}$ sessile nodule in the mid-descending colon.

Colorectal hemangiomas infrequently cause large bowel obstruction. ${ }^{38,39}$ A diffuse tumor may completely encircle the bowel wall, leading to luminal stenosis and obstruction. Polypoid lesions may rarely act as the lead point for intussusception. ${ }^{3,40}$ Large tumors of the rectum may cause constipation with tenesmus; defecation may exacerbate the bleeding. ${ }^{6}$

Allred and Spencer, ${ }^{25}$ in a case series of 29 patients from the Mayo experience, noted that $14 \%$ of patients had diarrhea.

\section{Physical Examination}

The presence of cutaneous hemangiomas (see earlier) may be an important clue to intestinal hemangioma being the cause of GI bleeding.

A large colonic hemangioma may be palpable as an abdominal mass. Similarly, a rectal hemangioma may be palpated on digital rectal examination as a soft ("doughy"), smooth, nodular, compressible mass that cannot be well outlined by the palpating finger. ${ }^{41}$

\section{INVESTIGATIONS}

\section{Laboratory Studies}

As discussed previously, abnormal findings may include anemia (of both the iron deficiency and acute blood loss varieties), thrombocytopenia, hypofibrinogenemia, coagulopathy, and decreased levels of factors V and VIII.

\section{Imaging}

Hollingsworth ${ }^{15}$ was the first to report the association of a narrowing of the sigmoid colon on barium enema with an area of surrounding phleboliths in a 9-year-old girl who had previously been operated on for peripheral hemangiomas.

\section{PLAIN ABDOMINAL FILMS}

Phleboliths are calcified, well-circumscribed densities (usually multiple) particularly associated with colonic cavernous hemangiomas. They are present in up to $50 \%$ of cases and do not reliably indicate the extent, nature, or number of the hemangiomas present. ${ }^{31}$ This is because development of radiographically visible phleboliths is a gradual process, and thrombosis, which leads to phlebolith formation, is primarily limited to the portion of the tumor within the colonic wall, so that soft tissue extension is not visualized. One should be suspicious that pelvic phleboliths may reflect the presence of a hemangioma when observed to be clustered in atypical locations (more caudal and medial) in a young patient. $^{4,42}$ In contrast, less than $5 \%$ of normal subjects show any radiographic evidence of pelvic phleboliths prior to the third decade. ${ }^{14}$ Lateral radiography distinguishes phleboliths in the presacral space from the more common anterior phleboliths in the pelvic venous plexus. ${ }^{5,20}$ Large hemangiomas of the rectum may cause displacement or distortion of the rectal air column seen on plain films. ${ }^{43}$

\section{BARIUM ENEMA}

Barium contrast studies are most useful for identifying polypoid or obstructing lesions. Features characteristic of a hemangioma on contrast enema are:

- Presence of a luminal filling defect, especially "scalloping" of the rectal wall produced by nodular elevations of hemangiomatous tissue ${ }^{42}$

- Narrowing of the distal rectosigmoid ${ }^{4,43}$

- Widening of the prerectal space as a mass effect of the lesion $^{43}$

Displacement of small bowel loops may provide an indication of the true dimensions of the tumor. The more rigid the affected bowel loops are, the older the lesions are, as a consequence of chronic inflammation with scarring of the bowel wall. ${ }^{5}$

\section{COMPUTED TOMOGRAPHY SCAN}

Although CT can be useful in confirming the presence of the tumor in the form of heterogeneous thickening of the bowel wall and engorged vessels in the perirectal fat, it has a more important role in defining the extent of the lesion and the presence of invasion into the mesentery or surrounding structures. ${ }^{33}$

\section{SELECTIVE MESENTERIC ANGIOGRAPHY}

Selective mesenteric angiography can detect the hemangioma even in the absence of active bleeding. The vascular malformation takes the form of venous pooling or "puddling," most commonly in the rectosigmoid region. It is also very useful for detecting synchronous lesions. ${ }^{5}$ Delayed-phase studies assist in demonstrating large venous malformations. ${ }^{4}$ However, thrombosis within these tumors may cause them to appear hypovascular or avascular, thus obscuring the true extent of the lesion. ${ }^{10}$

\section{MAGNETIC RESONANCE IMAGING}

MRI (Fig. 2) provides detailed anatomic images as well as being able to demonstrate blood flow anomalies without the need for contrast medium. ${ }^{44} \mathrm{~T} 2$-weighted images (more clearly depicted with fat suppression) show a markedly thickened rectosigmoid wall with very high signal intensity. ${ }^{19,45,46}$ Thrombosed vessels within the 


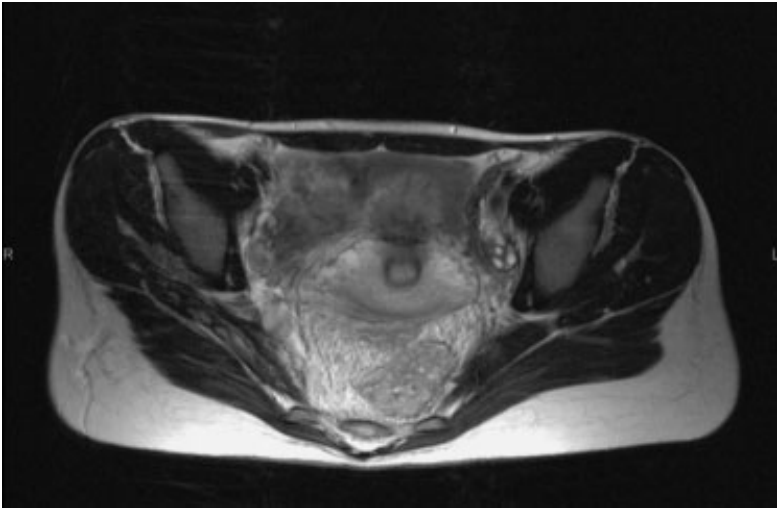

Figure 2 T2-weighted magnetic resonance image of the pelvis demonstrating increased signal intensity of the submucosal layer, infiltrating through the bowel wall and throughout the perirectal fat, consistent with rectal hemangioma. (Courtesy of Dr. C. Menias, St. Louis, MO.)

tumor mass appear as tubular structures with high signal intensity. Addition of an endorectal surface coil, as in endorectal ultrasonography, is able to evaluate the extent of tumor invasion through the five separate layers of the bowel wall and the sphincter muscles. ${ }^{44}$

\section{ENDOSCOPY}

Colonoscopy is essential in the evaluation of these patients. Hemangiomas appear as submucosal projections, ranging from a deep blue to a dull red ("plum" colored). ${ }^{6,43}$ Although frank ulceration is usually not visible, there may be several pinpoint bleeding areas. The tumors collapse on insufflation. ${ }^{31}$ The overlying rectal mucosa is edematous, suggesting chronic inflammation, which may lead the endoscopist to form the alternative (but erroneous) diagnosis of inflammatory bowel disease. $^{3,17,20,31}$

The proximal extent of the lesion should be determined. In the stable patient with no active bleeding, a complete survey of the colon and the upper GI tract is important to exclude synchronous lesions. Biopsy may cause severe hemorrhage and is usually contraindicated. $^{4,20,25,31,42,47}$ Nevertheless, Wang ${ }^{48}$ has suggested that biopsy of a carefully selected area may be useful in confirming the diagnosis.

\section{TREATMENTS}

Operative resection remains the recommended treatment, whenever possible, for colorectal hemangiomas because of the high risk of recurrent bleeding. Nonoperative therapy (as described in the following) is limited, for the most part, to case reports with little long-term follow-up.

Local control of bleeding (e.g., hemorrhoidectomy) has had little success. ${ }^{17}$ Early conservative measures were complicated by rebleeding. Gabriel ${ }^{49,50}$ reported success with ligation of the arteries feeding the lesion, but this technique appears unreliable as subsequent bleeding has occurred in other patients. ${ }^{12}$ Bancroft ${ }^{13}$ ligated the superior hemorrhoidal vein and injected it distally with $10 \mathrm{~mL}$ of $40 \%$ sodium salicylate. Despite initial success, the hemangioma recurred over the course of 20 years and ultimately required abdominoperineal resection. ${ }^{51}$

\section{Pharmacological Therapy}

To date, there are no known pharmacological agents that have been shown to be efficacious for intestinal hemangiomas. Steroids have been used in the treatment of infantile cutaneous hemangiomas, with a response rate of 30 to $60 \% .^{52,53}$ Interferon- $\alpha 2 \mathrm{a}$ has been shown to be effective in inducing regression of life-threatening, steroid-resistant hemangiomas of infancy, but none of the 20 patients in this study had known intestinal lesions. ${ }^{54}$

\section{Radiotherapy}

Irradiation of vascular tissue induces proliferation of the intima and fibrous sclerosis of the walls, sometimes with fibrinoid changes and occlusion by fibrin thrombi and development of arteriosclerosis. ${ }^{55}$ Radiation therapy has been successful in controlling bleeding from rectal tumors ${ }^{41,55,56}$ but would not appear to be appropriate for nonrectal lesions because of the toxicity to the adjacent organs.

\section{Endoscopic Therapy}

Polypoid tumors with a narrow base can be removed by snare polypectomy with electrocautery. ${ }^{57-59}$ However, such patients should be observed closely for postprocedure bleeding. ${ }^{60}$ Azizkhan ${ }^{9}$ described a patient with a diffuse rectosigmoid hemangioma who, after failing excision and oversewing, then sclerotherapy, was having daily massive episodes of hematochezia by age 17 . Argon laser therapy resulted in almost complete remission of his bleeding. Despite these successes, both patient and endoscopist must be aware of the risk of inducing uncontrollable hemorrhage and the need for emergent laparotomy if this occurs.

\section{OPERATIVE MANAGEMENT}

Choice of operation for patients with rectosigmoid lesions includes limited colon resection, low anterior proctosigmoidectomy with colorectal anastomosis, modified Parks coloanal pull-through, or abdominoperineal resection with end colostomy. Up until 1976, abdominoperineal resection was the procedure of choice for the resection of hemangiomas involving the distal rectum. $4,18,20,51,61,62$ 
Since then, sphincter preservation using rectal mucosectomy and pull-through coloanal sleeve anastomosis has become the first-line procedure in these usually young patients with benign disease. After the first ileoanal anastomosis after rectal resection was described in 1947 by Ravitch and Sabiston, ${ }^{63}$ Soave in $1964^{64}$ refined this technique in children with Hirschsprung's disease to include rectal resection with mucosectomy of the retained muscular rectal cuff and a coloanal pull-through anastomosis. This was further modified by Parks ${ }^{65}$ for the removal of villous adenomas of the rectum. The concept is to remove the hemangiomatous colon but to leave the abnormal rectum in situ. It is important to obtain early control of the inferior mesenteric artery. ${ }^{31}$ Limited pelvic dissection lessens the likelihood of severe intraoperative bleeding, hematoma formation, and damage to hypogastric, lumbar, and sacral nerves. ${ }^{66}$ A surgical plane seems to persist between the mucosa and the underlying muscularis, which permits successful removal of the rectal mucosal sleeve. ${ }^{67}$ The normal distal colon is then drawn down through the remaining muscularis cuff. The hemangiomatous vessels remaining in the rectal wall are no longer subjected to any local trauma, consequently reducing the risk of further bleeding. ${ }^{17}$ Cunningham et $\mathrm{al}^{47}$ recommended leaving a short ( 3 to $4 \mathrm{~cm}$ ) rectal cuff to minimize the amount of retained hemangioma.

In 1994, Londono-Schimmer et $\mathrm{al}^{66}$ reported the long-term results of 15 patients treated using this method. There were no perioperative deaths, and complications included one leak with abscess formation and two perianastomotic hematomas. Three patients were lost to follow-up. Of the remainder, three patients had rare sporadic bleeding after wiping, one had a rectal cuff abscess, and another had occasional incontinence.

\section{Management of Hemangiomatosis}

Operative management of hemangiomatosis is confounded by the large number of lesions distributed throughout the GI tract, all of which are at high risk of ulceration and hemorrhage. In the actively bleeding patient, angiography and tagged red cell scans may assist in localizing the specific source lesion. Definitive management remains poorly defined. Wong and Lau ${ }^{68}$ recommended an aggressive surgical approach in describing a patient with BRBNS who, in a single operation, underwent excision of a total of 69 hemangiomas - 3 gastric, 1 duodenal, 59 jejunoileal, 3 colonic, 1 rectal, and 2 on the surface of the liver. This was accomplished through a combination of segmental resections, wedge resections, right hemicolectomy, and simple excisions through colotomies. The patient had an uneventful postoperative course and was discharged home on postoperative day 9. At 18 month follow-up, he was well with no recurrent bleeding.
There are several case reports describing endoscopic management of hemangiomatosis. Endoscopic laser photocoagulation has been reported as successfully treating numerous widespread lesions in patients with BRBNS. ${ }^{69-71} \mathrm{Bak}$ et $\mathrm{al}^{72}$ used the snare polypectomy technique to remove some 18 colonic lesions over three sessions. Five lesions in the second part of the duodenum were also removed, and eight gastric lesions were banded. There were no complications, with no evidence of recurrent tumors or bleeding on repeated upper and lower endoscopies at 2 months. Shimada et $\mathrm{al}^{73}$ took this approach further in another patient with BRBNS-associated hemangiomatosis. After endoscopic ablation of three gastric and seven colonic hemangiomas by electrosurgical snare, this patient underwent a laparotomy in which two enterotomies enabled endoscopic snare excision of 39 small intestinal cavernous hemangiomas. One year after an uncomplicated recovery, a combination of panendoscopy and small bowel contrast follow-through examination revealed no new or remaining lesions.

\section{ACKNOWLEDGMENTS}

The authors would like to thank Dr. C. Menias, of the Mallinckrodt Institute of Radiology, and Dr. J. Ritter, of the Department of Pathology, both of Washington University School of Medicine in St. Louis, MO, for providing the images.

\section{REFERENCES}

1. Weiss SW. Histological Typing of Soft Tissue Tumours. 2nd ed. Berlin: Springer-Verlag; 1994:31

2. Phillips B. Surgical cases. London Med Gaz 1839;23:514517

3. Gentry RW, Dockerty MB, Clagett OT. Vascular malformations and vascular tumors of the gastrointestinal tract. Int Abstr Surg 1949;88:281-323

4. Coppa GF, Eng K, Localio SA. Surgical management of diffuse cavernous hemangioma of the colon, rectum and anus. Surg Gynecol Obstet 1984;159:17-22

5. Dachman AH, Ros PR, Shekitka KM, Buck JL, Olmsted WW, Hinton CB. Colorectal hemangioma: radiologic findings. Radiology 1988;167:31-34

6. Fenoglio-Preiser CM, Pascal RR, Perzin KH. Atlas of Tumor Pathology, Second Series, Fascicle 27: Tumors of the Intestines. Washington: Armed Forces Institute of Pathology; 1990:473-483

7. Murray-Lyon IM, Doyle D, Philpott RM, Porter NH. Haemangiomatosis of the small and large bowel with histological malignant change. J Pathol 1971;105:295-297

8. Servelle M. Klippel-Trenaunay syndrome-768 operated cases. Ann Surg 1985;201:365-373

9. Azizkhan RG. Life-threatening hematochezia from a rectosigmoid vascular malformation in Klippel-Trenaunay syndrome: long-term palliation using an argon laser. J Pediatr Surg 1991;26:1125-1128

10. Bortz JH. Diffuse cavernous hemangioma of the rectum and sigmoid. Abdom Imaging 1994;19:18-20 
11. Demircan O, Sonmez H, Zeren S, Cosa E, Bicakci K, Ozkan S. Diffuse cavernous hemangioma of the rectum and sigmoid colon. Dig Surg 1998;15:713-715

12. Scott WM, Brand NE. Giant hemangioma of the rectum. Br J Surg 1957;45:294-299

13. Bancroft FW. Haemangioma of sigmoid and colon. Ann Surg 1931;94:828-838

14. Ghahremani GG, Kangarloo H, Volberg F, Meyers MA. Diffuse cavernous hemangioma of the colon in the KlippelTrenaunay syndrome. Radiology 1976;118:673-678

15. Hollingsworth G. Haemangiomatous lesions of the colon. $\mathrm{Br}$ J Radiol 1951;24:220-222

16. Nader PR, Margolin F. Hemangioma causing gastrointestinal bleeding. Am J Dis Child 1966;111:215-222

17. Jeffery PJ, Hawley PR, Parks AG. Colo-anal sleeve anastomosis in the treatment of diffuse cavernous haemangioma involving the rectum. Br J Surg 1976;63:678-682

18. Bland KI, Abney HT, MacGregor AMC, Hawkins IF. Hemangiomatosis of the colon and anorectum. Am Surg 1974;40:626-635

19. Djouhri H, Arrive L, Bouras T, Martin B, Monnier-Cholley L, Tubiana JM. MR imaging of diffuse cavernous hemangioma of the rectosigmoid. AJR Am J Roentgenol 1998;171: 413-417

20. Lyon DT, Mantia AG. Large-bowel hemangiomas. Dis Colon Rectum 1984;27:404-414

21. Schoen FJ, Cotran RS. Blood vessels. In: Cotran RS, Kumar V, Collins T, eds. Robbins Pathologic Basis of Disease, 6th ed. Philadelphia: WB Saunders; 1999:532-533

22. Gascoyen M. Case of naevus including the parotid gland and causing death from suffocation-naevi of viscera. Trans Pathol Soc London 1860;11:267-269

23. Geschickter CF, Keasbey LE. Tumors of blood vessels. Am J Cancer 1935;23:568-591

24. Kaijser R. Uber hamangiome des tractus gastrointestinalis. Archiv Klin Chir 1936;187:351-388

25. Allred HW, Spencer RJ. Hemangiomas of the colon, rectum and anus. Mayo Clin Proc 1974;49:739-741

26. Pohlen U, Kroesen AJ, Berger G, Buhr HJ. Diagnostics and surgical treatment strategy for rectal cavernous hemangiomas based on three case examples. Int J Colorectal Dis 1999;14: 300-303

27. Rissier HL Jr. Hemangiomatosis of the intestine-discussion, review of the literature and report of two new cases. Gastroenterologia 1960;93:357-369

28. Kempson RL, Fletcher CD, Evans HL, Hendrickson MR, Sibley RK. Atlas of Tumor Pathology, Third Series, Fascicle 30: Tumors of the soft tissues. Washington, DC: Armed Forces Institute of Pathology; 2001:307-367

29. Head HD, Baker JQ, Muir RW. Hemangioma of the colon. Am J Surg 1973;126:691-694

30. Brizel HE, Raccuglia G. Giant hemangioma with thrombocytopenia: radioisotopic demonstration of platelet sequestration. Blood 1965;26:751-756

31. Aylward CA, Orangio GR, Lucas GW, Orangio VW. Diffuse cavernous hemangioma of the rectosigmoid-CT scan, a new diagnostic modality, and surgical management using sphincter-saving procedures: report of three cases. Dis Colon Rectum 1988;31:797-802

32. Hall GW. Kasabach-Merritt syndrome: pathogenesis and management. Br J Haematol 2001;112:851-862

33. Perez C, Andreu J, Llauger J, Valls J. Hemangioma of the rectum: CT appearance. Gastrointest Radiol 1987;12:347-349
34. Orangio GR. Nonepithelial colorectal tumors. In: Fazio VW, Church JM, Delaney CP, eds. Current Therapy in Colon and Rectal Surgery. Philadelphia: Elsevier Mosby; 2004:410 414

35. Tan TCF, Wang JY, Cheung YC, Wan WYL. Diffuse cavernous hemangioma of the rectum complicated by invasion of pelvic structures; report of two cases. Dis Colon Rectum 1998;41:1062-1066

36. Babcock WW, Jonas KC. Hemangioma of the colon. Am J Surg 1950;80:854-859

37. Condon RE, Loyd RD. Hemangioma of the colon. Am J Surg 1968;115:720-723

38. Buie LA, Swan T. Benign tumors of the colon. Surg Clin North Am 1929;9:893-910

39. Sawyer CF. Hemangioma of colon. Arch Surg 1939;39:987991

40. Gesslein M, Koscheck T, Kusch B. Capillary hemangioma of the colon as a rare cause of intussusception in adults. Dtsch Med Wochenschr 2004;129:1970-1972

41. Oppenheim A, O'Brien JP. Unusual anal, rectal and perirectal tumors palpable by rectal examination. Am J Surg 1950;79: 302-311

42. Stening SG, Heptinstall DP. Diffuse cavernous haemangioma of the rectum and sigmoid colon. Br J Surg 1970;57: 186-189

43. Amarapurkar D, Jadliwala M, Punamiya S, Jhawer P, Chitale A, Amarapurkar A. Cavernous hemangiomas of the rectum: report of three cases. Am J Gastroenterol 1998;93:1357-1359

44. Hasegawa $\mathrm{H}$, Teramoto $\mathrm{T}$, Watanabe $\mathrm{M}$, et al. Diffuse cavernous hemangioma of the rectum: MR imaging with endorectal surface coil and sphincter-saving surgery. J Gastroenterol 1996;31:875-879

45. Lupetin AR. Diffuse cavernous hemangioma of the rectum: evaluation and MRI. Gastrointest Radiol 1990;15:343-345

46. Yorozuya K, Watanabe M, Hasegawa $\mathrm{H}$, et al. Diffuse cavernous hemangioma of the rectum: report of a case. Surg Today 2003;33:309-311

47. Cunningham JA, Garcia VF, Quispe G. Diffuse cavernous rectal hemangioma-sphincter-sparing approach to therapy. Dis Colon Rectum 1989;32:344-347

48. Wang C-H. Sphincter-saving procedure for treatment of diffuse cavernous hemangiomas of the rectum and sigmoid colon. Dis Colon Rectum 1985;28:604-607

49. Gabriel WB. The Principles and Practice of Rectal Surgery. 4th ed. London: Lewis; 1948:280

50. Gabriel WB. The Principles and Practice of Rectal Surgery. 5th ed. Springfield, IL: Charles C Thomas; 1963:116-118

51. Jaques AA. Cavernous hemangioma of the rectum and rectosigmoid colon. Am J Surg 1952;84:507-509

52. Bartoshesky LE, Bull M, Feingold M. Corticosteroid treatment of cutaneous hemangiomas: how effective? A report on 24 children. Clin Pediatr (Phila) 1978;17:625-638

53. Akyuz C, Yaris N, Kutluk MT, Buyukpamukcu M. Management of cutaneous hemangiomas: a retrospective analysis of 1109 cases and comparison of conventional dose prednisolone with high-dose methylprednisolone therapy. Pediatr Hematol Oncol 2001;18:47-55

54. Ezekowitz RAB, Mulliken JB, Folkman J. Interferon alfa-2a therapy for life-threatening hemangiomas of infancy. N Engl J Med 1992;326:1456-1463

55. Chaimoff $\mathrm{C}$, Lurie $\mathrm{H}$. Hemangioma of the rectum: clinical appearance and treatment. Dis Colon Rectum 1978;21:295296 
56. Chaimoff C. On the treatment of hemangioma of the rectum. Dis Colon Rectum 1985;28:632

57. Fraiberg EN, Ahmed S. Colonoscopic excision of a polypoidal cavernous hemangioma of the cecum. Gastrointest Endosc 1985;31:109

58. Liang L, Forbes N, David J, Ozick L. Endoscopic polypectomy of an unusually long polypoid colorectal cavernous hemangioma. Gastrointest Endosc 1998;47:307-308

59. Levitt RE. Colonic cavernous hemangioma. Gastrointest Endosc 1998;48:337

60. Benson JM, Orlay G. Colorectal haemangioma and its relationship to haemorrhoids in childhood. Aust N Z J Surg 1991;61:537-540

61. Hellstrom J, Hultborn KA, Engstedt L. Diffuse cavernous hemangioma of the rectum. Acta Chir Scand 1955;109:277283

62. Westerholm P. A case of diffuse haemagiomatosis of the colon and rectum. Acta Chir Scand 1967;133:173-176

63. Ravitch MM, Sabiston DC. Anal ileostomy with preservation of the sphincter: a proposed operation in patients requiring total colectomy for benign lesions. Surg Gynecol Obstet 1947; 84:1095-1099

64. Soave F. A new surgical technique for treatment of Hirschsprung's disease. Surgery 1964;56:1007-1014

65. Parks AG. Benign tumours of the rectum. In: Rob C, Smith R, Morgan CN, eds. Clinical Surgery. Vol 10. Abdomen and Rectum and Anus. London: Butterworths; 1966:541-548
66. Londono-Schimmer EE, Ritchie JK, Hawley PR. Coloanal sleeve anastomosis in the treatment of diffuse cavernous haemangioma of the rectum: long-term results. Br J Surg 1994;81:1235-1237

67. Telander RL, Blaufuss MC. Rectal mucosectomy: a definitive approach to extensive hemangiomas of the rectum. J Pediatr Surg 1993;28:379-381

68. Wong SH, Lau WY. Blue rubber-bleb nevus syndrome. Dis Colon Rectum 1982;25:371-374

69. Shahed M, Hagenmuller F, Rösch T, et al. A 19-year-old female with blue rubber bleb nevus syndrome: endoscopic laser photocoagulation and surgical resection of gastrointestinal angiomata. Endoscopy 1990;22:54-56

70. Manoury V, Turck D, Brunetaud JM, et al. Blue rubber bleb nevus syndrome: three cases treated with Nd:YAG laser and bipolar electrocoagulation. Gastroenterol Clin Biol 1990;14: 593-595

71. Morris L, Lynch PM, Gleason WA, Schauder C, Pinkel D, Duvic M. Blue rubber bleb nevus syndrome: laser photocoagulation of colonic hemangiomas in a child with microcytic anemia. Pediatr Dermatol 1992;9:91-94

72. Bak Y-T, Oh CH, Kim JH, Lee CH. Blue rubber bleb nevus syndrome: endoscopic removal of the gastrointestinal hemangiomas. Gastrointest Endosc 1997;45:90-92

73. Shimada S, Namikawa K, Maeda K, et al. Endoscopic polypectomy under laparotomy throughout the alimentary tract for a patient with blue rubber bleb nevus syndrome. Gastrointest Endosc 1997;45:423-427 